Artículo de reflexión

Cuestiones de filosofía

ISSN: 0123-5095

Vol. 2 - No. 19

Julio - dciembre, año 2016

pp. $87-104$

\title{
Conflicto y progreso en los textos de Kant sobre filosofía de la historia*
}

\author{
Conflict and progress in the works of \\ Kant about philosophy of history
}

Gerardo Ambriz-Arévalo**

Universidad Autónoma Metropolitana-Iztapalapa

México

Fecha de recepción: 7 de julio del 2016

Fecha de evaluación: 3 de agosto del 2016

Fecha de aceptación: 6 de octubre del 2016

* Artículo de reflexión.

** Doctor en Humanidades por la Universidad Autónoma Metropolitana-lztapalapa. Ciudad de México.irmonger@hotmail.com 


\title{
Resumen
}

En elámbito de la filosofía política contemporánea, el tema del conflicto social ha ido adquiriendo una inédita relevancia. En la actualidad no faltan escritos donde se discute la validez del concepto de Marx sobre la lucha de clases, y no son pocos los que abordan el concepto de lucha por el reconocimiento, elaborado por Hegel en sus primeras obras. Infortunadamente, la gran cantidad de trabajos sobre estos paradigmas han opacado los pocos, y no menos relevantes, que se han hecho sobre el papel que Kant le otorga al conflicto social en su filosofía de la historia. Para no dejar en el olvido a Kant, este artículo ofrece un análisis de su concepción del conflicto social, pero centrado en la función que tiene como motor que impulsa el progreso moral de las sociedades, es decir, la idea kantiana de que gracias al antagonismo social (a la insociable sociabilidad) se han ido consolidando y ampliando derechos que, bajo ciertas circunstancias, pueden contribuir a la convivencia respetuosa y pacífica entre individuos y Estados.

Palabras clave: Conflicto social, Filosofía de la historia, Kant, Progreso moral, Sociabilidad; Estado.

\begin{abstract}
In the field of contemporary political philosophy, the topic of social conflict has been acquiring a relevance without precedents. Currently, writing pieces discussing the validity of the concept of struggle for recognition, developed by Hegel in his early works, are common. Unfortunately, a great amount of studies about these paradigms have overshadowed the few, but not less relevant, that have been made about the role that Kant attributes to social conflict in his philosophy of history. In order to keep Kant inside the picture, this article offers an analysis of his conception of social conflict, nevertheless focused on its function as a driving force that boosts the moral progress of societies, in other words, the Kantian idea which affirms that thanks to social antagonism (or unsociable sociability) human rights that, under certain circumstances, might contribute to the respectful and peaceful coexistence between individuals and states, have been consolidated and expanded.
\end{abstract}

Key words: Social conflict, Philosophy of History, Kant, moral progress, sociability, state. 


\section{INTRODUCCIÓN}

Actualmente se escribe mucho sobre el papel que juega el conflicto social en el desarrollo de la historia o de las sociedades; la mayoría de los análisis se inscriben dentro de dos de los grandes paradigmas filosóficos: el marxismo y el hegelianismo; respecto al primero, sería imposible mencionar a todos los autores que, partiendo de la idea de que "la historia de todas las sociedades existentes hasta el presente es la historia de la lucha de clases" (Marx/Engels, 1998, p. 38), han mostrado que solo con la lucha política de los trabajadores contra las relaciones sociales capitalistas se puede alcanzar un tipo de sociedad más justa y libre de explotación²; respecto al segundo paradigma, será Axel Honneth quien, con base en la obra temprana de $\mathrm{Hegel}^{3}$, intente desarrollar el concepto de "lucha por el reconocimiento", que pretende "sacar a la luz la lógica moral de los conflictos sociales" (Honneth, 1997, p. 8) y distinguir tres formas de reconocimiento (el amor, el derecho y la valoración), que son indispensables para el desarrollo y "la autorrealización individual" (Honneth, 1997, p. 208) $)^{4}$.

No obstante, la importancia de estos dos marcos teóricos para analizar el conflicto social y su papel en la historia, creo que se ha dejado fuera lo que al respecto dijo Kant, incluso antes que Hegel y Marx; por tal motivo, el objetivo de este trabajo es, simplemente, exponer la idea de Kant acerca del progreso moral e intelectual, pero tratando de mostrar la función que tiene el conflicto social en dicho progreso. Para ello, me basaré, principalmente, en algunos textos poco explorados: Idea de una historia universal con propósito cosmopolita, El conflicto de las facultades y Pedagogía.

Dicho lo anterior, empiezo diciendo que en la obra Idea de una historia universal con propósito cosmopolita, Kant nos invita a entender la historia como una disciplina que puede dar cuenta, más que del despliegue de la libertad de la voluntad en términos metafísicos (Kant, 1999, p. 73), de cómo las acciones humanas pueden

2 Domenico Losurdo (2013) es uno de los autores actuales que han estudiado de forma rigorosa el concepto de lucha de clases en Marx.

3 Hegel (1984), Hegel (2006). Charles Taylor (2003) también ha echado mano, para desarrollar su tesis sobre el multiculturalismo, del concepto de "reconocimiento" de Hegel.

4 El mismo Axel Honneth (2009) ha intentado vincular su concepción de la lucha por el reconocimiento a la moral kantiana en su ensayo "Entre Aristóteles y Kant. Esbozo de una moral del reconocimiento". 
ser entendidas si se analizan con detenimiento, y en su conjunto, como acciones que avanzan progresivamente y con cierto orden, ya que se pueden encontrar regularidades en ellas que pueden ser comparables a las regularidades o leyes de la naturaleza. En otras palabras:

Las acciones humanas, como cualquier otro acontecimiento natural, están determinadas por leyes generales de la naturaleza. La historia, que se ocupa de la narración de estos fenómenos, nos hace esperar, por profundas que puedan ser sus causas remotas, que, al observar el juego de la libertad de la voluntad humana en grande, se puede descubrir en ella una marcha regular; igual que se puede llegar a conocer el conjunto de la especie, como un desarrollo en marcha constante, aunque lenta, de sus disposiciones originales, aquello que se ofrece confuso e irregular a la mirada en los sujetos particulares (Kant, 1999, p. 73).

La última parte de la anterior cita es muy interesante, pues Kant advierte que las regularidades del actuar humano pueden ser captadas si, y solo si, todas las acciones se estudian en su conjunto y no de manera aislada, como hace la gente que no se dedica a estos temas; es decir, si se analizan por separado, los hechos humanos no arrojarían ningún resultado, ni acerca de dónde venimos ni hacia dónde nos dirigimos, puesto que solo se vería caos, irregularidad, accidentalidad y decadencia. El ejemplo que pone Kant al respecto es muy claro, ya que menciona, por un lado, que las mentes no tan atentas ${ }^{5}$ verán en los matrimonios, los nacimientos y las muertes humanas acciones caóticas o contingentes; mientras que, por el otro, las miradas científicas observarán esos mismos acontecimientos humanos como leyes perfectamente medibles y detectables, dado que presentan alguna regularidad (Kant, 1999).

No obstante, esta visión kantiana de la historia, no se debe creer que, por el hecho de hablar de leyes o regularidades en las acciones humanas, el filósofo de Könisberg haya creído que la historia humana esté predestinada a algo, y que se pueda planear

5 Otfried Höffe no solo menciona a personas ajenas a la ciencia de la historia que no se dan cuenta, ni les importa, del sentido de la historia, sino que también atribuye esta carencia a historiadores empíricos: "Kant no investiga la historia en toda la variedad de sus acontecimientos concretos; deja esta tarea «a la historia de tipo empírico»... Se ocupa de la historia en tanto que interesa al hombre como ser racional práctico. Enlazando con la crítica trascendental de la razón, pregunta en qué condiciones no empíricas aparece la historia como algo racional y dotado de un sentido" (Höffe, 1986, p. 226). 
con exactitud milimétrica cada acontecimiento. Kant está muy lejos de todo determinismo o fatalismo; tampoco hay indicios en su obra de que afirme que las acciones humanas son mecánicas o totalmente instintivas, como en los animales. "No parece -dice Kant-que sea posible historia alguna planificada... pues los hombres no proceden en conjunto, en sus aspiraciones, de manera meramente instintiva, como animales, ni tampoco, como ciudadanos racionales del mundo, según un plan prefijado" (Kant, 1999, p. 74).

Ahora bien, Kant, en la obra que se ha venido citando, propondrá en nueve tesis una idea de la historia universal que lleva implícito un hilo racional que la va guiando hacia un progreso constante. En la primera tesis, según la entiendo, intentará mostrar que sería contradictorio, y hasta irracional, pensar que una disposición natural, sea humana, animal o vegetal, no se dirige a un fin, que sería el de desarrollarse cabalmente. Si negamos a la naturaleza dicha teleología, advierte Kant, caeríamos en el pesimismo total, pues lejos de creer en un orden conducido por la razón hacia una situación mejor, pensaríamos que la historia y la naturaleza se despliegan de manera caótica o irracional, para ir de algo malo a algo todavía peor. Asíenuncia Kant su primer principio sobre la historia: "Todas las disposiciones naturales de una criatura están determinadas a desarrollarse alguna vez de manera completa y adecuada" (Kant, 1999, p. 75).

La teleología en la naturaleza no fue tratada por Kant únicamente en la Idea de una historia universal, pues también aparece en sus obras más importantes, como el caso de la Crítica del juicio, específicamente en el parágrafo 83, donde afirma que el fin último de la naturaleza es la felicidad y la cultura del hombre:

Hemos mostrado en lo que precede que tenemos motivo suficiente, según principios de la razón, para juzgar al hombre, no sólo, igual que los seres organizados todos, como fin de la naturaleza, sino también aquí, en la Tierra, como el último fin de la naturaleza, en relación con el cual todas las demás cosas naturales constituyen un sistema de fines [...]. El primer fin de la naturaleza sería la felicidad; el segundo, la cultura del hombre (Kant, 2007, p. 371).

En el segundo principio, Kant nos dice que "en los hombres (como únicas criaturas racionales sobre la Tierra) aquellas disposiciones naturales que aspiran al uso de su razón deben desarrollarse por completo sólo en la especie, pero no en el individuo" (Kant, 1999, p. 75). Aquí, el autor de Lo bello y lo sublime nos invita a pensar que la razón tiene tres características: en primer lugar, es una facultad que 
permite al ser humano, como especie, desarrollarse ilimitadamente más allá de lo que marca su instinto; en segundo lugar, es una facultad que no actúa ciegamente y que requiere de ensayos, ejercicios y aprendizajes (Kant, 1999) para que vaya escalando hacia un grado más alto de conocimiento, y en tercer lugar, la razón es una facultad que se ha ido desarrollando y transmitiendo de una generación a otra, lo cual ha permitido que no se pierda y que se perfeccione paso tras paso ${ }^{6}$.

El tercer principio kantiano sobre la filosofía de la historia es el siguiente: "La naturaleza ha querido que el hombre extraiga por completo de sí mismo todo cuanto sobrepasa el ordenamiento mecánico de su existencia animal, y que no participe de ninguna otra felicidad o plenitud que él mismo, libre del instinto, se procure mediante su propia razón" (Kant, 1999, p. 76). Kant explica este principio señalando que la naturaleza no procede ciegamente, pues dotó a los animales de cuernos y garras, para su autodefensa, y al género humano, de razón ${ }^{7}$ y libertad de la voluntad, con el fin de que se valiera de estas para su autoprotección y desarrollo moral. Protección y desarrollo que no serían posibles si el humano solo contara con sus precarios instintos o fuera una marioneta dirigida por algo externo a él, es decir, si en lugar de ejercer su autonomía fuera rehén de la heteronomía. Pero Kant no se queda ahí y vuelve a señalar, me parece, que el desarrollo humano no sería posible si tomamos de manera aislada, o hiciéramos borrón y cuenta nueva, de los disfrutes y penalidades que cada generación de individuos ha ido legando a la siguiente; si consideramos a cada hombre como un simple ser finito que, con más penas que glorias, nace, crece y muere sin dejar nada atrás. Dicho en palabras de Kant:

6 Lo que llama la atención de esta tesis es que Kant hable de un desarrollo de la razón del género humano y no de la razón de alguien en particular; esto significa, según Otfried Höffe, además de una tesis que se adelantó a la astucia de la razón, de Hegel, una hipótesis que se puede entender de la siguiente manera: "Esta tendencia natural de la humanidad debe hacerla realidad la propia naturaleza humana; el sentido de la historia, que es el progreso científico, se produce en cierto modo a nuestra espalda: con nuestro concurso y, sin embargo, al margen de nuestros planes" (Höffe, 1986, p. 229).

7 En su escrito Comienzo presunto de la historia humana, Kant señala más o menos lo mismo, pero se ve de forma más clara su creencia en que el ser humano, gracias a su capacidad racional, puede desarrollarse paulatinamente: "El primer hombre, por tanto, podía erguirse y andar, podía hablar, incluso discurrir, es decir, hablar mediante conceptos relacionados, por tanto, pensar. Destrezas puras que debió adquirir por sí mismo [...]; pero de las que ya lo supongo previsto para considerar sólo el desarrollo de lo moral en lo que hace o deja de hacer" (Kant, 1999, p. 147). 
Resulta muy extraño que las viejas generaciones parezcan laborar penosamente sólo para estimular a las siguientes y prepararles un grado sobre el que puedan alzar más alto el edificio que la naturaleza tiene de propósito; y que sólo las últimas hayan de tener el gozo de habitar en la casa que una serie larga de antepasados (desde luego que sin este propósito) ha levantado, sin pensar en tomar parte en la dicha que han preparado. Por extraño que sea, al mismo tiempo resulta necesario una vez supuesto que una especie animal debe tener razón y, como clase de seres racionales que mueren, en suma, aunque su especie sea inmortal, alcanzar una plenitud en el desarrollo de sus disposiciones (Kant, 1999, pp. 77-78).

Hasta aquí no me he detenido mucho en los principios de Kant sobre la historia, cosa que no ocurrirá respecto al cuarto, pues se analizará con más cuidado por ser, en mi opinión, la idea donde Kant se expresó de manera más explícita acerca del conflicto como el factor que impulsa el desarrollo humano o histórico basado en un orden legal. El principio es el siguiente: "El medio del que se sirve la naturaleza para lograr el desarrollo de todas sus disposiciones es el antagonismo de las mismas en la sociedad, hasta el extremo de que éste se convierte en la causa de un orden legal de aquellas" (Kant, 1999, p. 78). Y para empezar a explicar este principio, el mismo Kant dice que con antagonismo (conflicto) entiende la insociable sociabilidad de los hombres, donde estos, en su búsqueda de vivir en sociedad, siempre se toparán con una oposición que va en sentido opuesto, a saber, la insociabilidad. Más específicamente, Kant considera que el hombre tiene una especie de doble naturaleza que, por un lado, le impele a socializarse, y, por el otro, le empuja hacia la individualización.

Así las cosas, creemos que Kant no ve de forma negativa dicha oposición, y sí como algo positivo, pues la individualización no solo impulsa al hombre a salir de su letargo para ganarse su subsistencia, sino también a desarrollar cada vez más aquellas capacidades o talentos que le servirán para vivir moralmente en sociedad. A continuación, Kant nos da buenas razones para entender que si el hombre no tuviera esa parte egoísta (insociable) no sería posible el desarrollo individual o colectivo de la humanidad, ya que el talento en potencia de cada individuo estaría sujeto o domesticado por lo que dicta la tradición del conjunto de la sociedad:

Sin tales cualidades, apenas amables, por cierto, de la insociabilidad, de la que surge la resistencia que cada uno debe encontrar necesariamente por sus egoístas presunciones, todos los talentos permanecerían para siempre ocultos 
en su semilla, en una arcádica vida de pastores, logrando perfectos acuerdos, satisfacción y versatilidad: los Hombres, buenos como las ovejas que apacientan, apenas si otorgarían a su existencia un valor mayor del que posee su manso [vivir]; ni llenarían el vacío de la creación, respecto a su fin, como naturalezas racionales (Kant, 1999, p. 79).

Además de esto, Kant dará ejemplos donde se muestra la tensión constante que existe entre la parte egoísta y la parte sociable de los humanos, tensión que sirve como acicate para que las capacidades humanas prosperen y no se queden empantanadas. Él dice que mientras que el "hombre quiere concordia", su naturaleza insociable "quiere discordia", y mientras que el hombre "quiere vivir tranquilo y divertido... la naturaleza quiere que deba salir de la indolencia y del inactivo contento, que se arroje al trabajo y las penalidades para encontrar, por contraste, el medio de zafarse con sagacidad de ellos" (Kant, 1999). En suma, para Kant "los motivos naturales, las fuentes de la insociabilidad y de la resistencia en general, de donde brota tanto mal, pero que a su vez promueven nuevas tensiones de las fuerzas y, por tanto, un mejor desarrollo de las disposiciones naturales, delatan el ordenamiento de un creador sabio, y en modo alguno la mano de un espíritu maligno, que lo distraiga en su ejecución señorial o arruine su envidiado proceder (Kant, 1999).

Es importante señalar que si para Kant la tendencia de cada hombre es hacia su insociabilidad (individualidad), esto no quiere decir que le esté dando una importancia exclusiva a esta por encima de su parte sociable. Creo que la importancia de las dos partes es paralela, dado que si predominara la sociabilidad sobre la insociabilidad, no habría avance de ningún tipo, pues cualquier intento individual por sobresalir quedaría inmediatamente ahogado por la multitud, y viceversa, si predominara la insociabilidad sobre la sociabilidad, el trayecto de la humanidad sería deforme y caótico; sucedería lo que le pasaría al árbol en aquella metáfora que Kant plasma en alguno de sus escritos sobre pedagogía, que crecería torcido si no estuviera plantado en medio de otros árboles, o derecho si creciera en medio de otros árboles que, lo mismo que él, buscan la luz del sol: "El árbol plantado solo en un campo crece torcido y extiende sus ramas a lo lejos; por el contrario, el árbol que se alza en medio de un bosque, crece derecho, por la resistencia que le ponen los árboles próximos, y busca sobre sí la luz y el sol" (Kant, 2003a, p. 37).

Los escritos de pedagogía de Kant nos ofrecen muchos ejemplos o argumentos a favor del progreso humano (en este caso en el ámbito de la educación), que se 
hace efectivo cuando los hombres se interrelacionan, y no cuando se comportan como ascetas o ególatras en la soledad. Los ejemplos más significativos son aquellos donde Kant habla del desarrollo paulatino que ha habido en la educación, lo cual sería imposible si cada humano hubiera guardado sus conocimientos para él solo, y no los hubiera compartido con otros y transmitido a generaciones posteriores. Así, "la educación es un arte, cuya práctica ha de ser perfeccionada por muchas generaciones. Cada generación, provista de los conocimientos de las anteriores, puede realizar constantemente una educación que desenvuelva, de modo proporcional y conforme a un fin, todas las disposiciones naturales del hombre, y conducir así toda la especie humana a su destino (Kant, 2003a, p. 34).

El progreso humano también se aprecia en los escritos pedagógicos de Kant, específicamente cuando él se pronuncia como partidario de una educación que se dé en sociedad, es decir, solo una educación pública puede darle al humano lo que necesita para progresar, cosa que no pasaría si cada humano, o los que tuvieran la posibilidad, fueran educados en la comodidad (soledad) de sus casas, sin la interacción con sus semejantes: "Parece ser más ventajosa, en general, la educación pública que la privada, no sólo desde el punto de vista de la habilidad, sino también por lo que se refiere al carácter del ciudadano. Es muy frecuente que la educación doméstica no solamente no corrija las faltas de la familia, sino que las aumente" (Kant, 2003a, p. 42).

Pero Kant no solo habló de la educación en sociedad como factor de desarrollo en textos sobre pedagogía, también lo hizo en su obra El conflicto de las facultades, específicamente cuando responde a la pregunta: “¿Cuál es el único orden de cosas en que puede aguardarse el progreso hacia lo mejor?":

No por la marcha de las cosas desde abajo hacia arriba, sino desde arriba hacia abajo. Contar con que gracias a la formación de la juventud en la enseñanza del hogar y luego en la escuela, desde los niveles inferiores hasta los superiores, con una cultura humanista y moral reforzada por la doctrina religiosa, se llegará finalmente a educar, no sólo buenos ciudadanos, sino a educarlos para que puedan seguir progresando hacia el bien y mantenerse así (Kant, 2003b, pp. 169-170).

Creo que con lo visto hasta aquí podría afirmar, sin temor a equivocarme, que para Kant el progreso humano se da cuando el hombre, sin sacrificar su parte individualista o egoísta, vive y convive en sociedad. Pero cabe aclarar que con 
progreso del género humano no se está refiriendo a un desarrollo biológico, sino a un ascenso "con arreglo al conjunto de los hombres (universorum) vinculados en sociedad y diseminados como naciones sobre la faz del globo terráqueo" (Kant, 2003 b, p. 152). Pero el progreso se alcanza no por cualquier forma de conflicto. Si los conflictos son motivados exclusivamente por intereses egoístas, es obvio que nos encontraríamos en aquello que Hobbes describió como "insufrible situación de guerra" (Hobbes, 1992, p. 141), pues no se estaría hablando de progreso, sino de retroceso hacia lo peor, tal como Kant lo señala en El conflicto de las facultades, específicamente cuando nos habla de la concepción "terrorista" de la historia humana: 'La degeneración hacia lo peor no puede darse de continuo en el género humano, pues al alcanzar cierta cota se exterminaría a sí mismo. Por eso, cuando se acrecientan descomunalmente las atrocidades y los males que les son anejos, se dice que «esto ya no puede ir a peor»»" (Kant, 2003b, p. 154).

Hannah Arendt, en sus comentarios sobre la filosofía política de Kant, reconoce que el filósofo pone más énfasis en la parte sociable que en la parte individual (o insociable) del ser humano, la cual es el factor que impulsa el desarrollo histórico de la humanidad en general. La autora alemana dice que "ni los individuos históricos, ni nada que los hombres hicieran de bueno o de malo, sino que lo que importa es la secreta astucia de la naturaleza que originó el progreso de las especies y el desarrollo de sus potencialidades en la serie de generaciones. La duración de una existencia individual es demasiado breve para desarrollar todas las cualidades y posibilidades humanas" (Arendt, 2003, p. 24).

Las consecuencias negativas que se derivarían de una sociedad donde predomina la insociabilidad, el egoísmo o el solipsismo puede trasladarse a lo que Otfried Höffe, siguiendo a Kant, postula en su obra El proyecto político de la modernidad respecto a cuestiones de teoría del conocimiento: ahí señala que el desarrollo del conocimiento se vería truncado, lo mismo que el desarrollo moral, por una pretensión egoísta de alguien que se cree la medida de todo el conocimiento, y no piensa que sea necesario un diálogo con los demás para poner a prueba su supuesta verdad. En este caso, Höffe no pone como dicotomía la insociable sociabilidad, sino el egoísmo frente al pluralismo:

Lo opuesto al pluralismo se encuentra en este caso no en una sociedad uniforme, sino en el sujeto satisfecho consigo mismo, el sujeto "egoísta" (solipsista) en lugar de comunicativo. Mientras que el egoísta lógico compara todos los juicios sólo con el propio, porque tiene la concordancia 
correspondiente con un criterio suficiente de la verdad, el pluralista lógico compara sus conocimientos con los de otros y determina la verdad a través de la concordancia con ellos. El egoísta lógico, conforme con la validez privada de un punto de vista, transforma todo el presunto conocimiento en pura apariencia, pues el conocimiento encierra la pretensión de validez universal (Höffe, 2008, p. 56).

Es pertinente la cita de Otfried Höffe porque nos ayuda a seguir avanzando y a comprender todavía más que el progreso en Kant se encuentra en muchas de sus obras, unas veces vinculado a la moral, otras a la historia, unas cuantas a la educación y otras muchas al progreso de la razón y del conocimiento. Su principal obra, Crítica de la razón pura, no es la excepción, pues en ella nos advierte que solo una razón que es puesta a debate público, o a crítica desinhibida, puede avanzar hacia mejor, porque cuenta con el consenso de todos; sin la exclusión de nadie:

La razón, en todas sus empresas, debe someterse a la crítica, y no puede menoscabar la libertad de ésta con ninguna prohibición, sin perjudicarse a sí misma y sin atraer sobre sí una sospecha que le es desfavorable. No existe nada tan importante, en lo que toca al provecho, nada tan sagrado, que pueda sustraerse a esta inspección que controla y que examina, y que no conoce acepción de personas. En esa libertad se basa incluso la existencia de la razón, que no tiene autoridad dictatorial, sino que la sentencia de ella es siempre sólo el consenso de ciudadanos libres, cada uno de los cuales debe poder expresar sin reservas sus escrúpulos e incluso su veto (Kant, 2009: p. 647).

Este mismo fragmento es citado por Dulce María Granja, pero con el propósito de encontrar los más importantes pasajes de la obra de Kant que nos permitan una teoría más sólida acerca de su concepto de publicidad. Ella retoma esta cita de Kant para mostrarnos que el principio de publicidad no se quedó en su simple formulación en Hacia la paz perpetua, ya que se encuentra en varias de sus obras, pero de manera implícita, y sin mencionar que se trata de dicho principio. Esto se ve claramente si leemos con cuidado la anterior cita de la Crítica de la razón pura, donde habla del uso polémico de la razón. La profesora Granja lo comenta de la siguiente manera:

Kant entiende por uso polémico de la razón pura la defensa de los enunciados racionales contra las negaciones dogmáticas de los mismos. Para Kant, este uso polémico de la razón es anterior y meramente preparatorio con respecto 
a la labor crítica, labor que consiste en realizar un examen de los límites y alcances precisos de la razón” (2010, pp. 184-185).

Sobre el principio de publicidad no ahondaremos más, pues es un tema que desborda los límites de este trabajo; baste con señalar que dicho principio, según Dulce María Granja, "no significa solamente comunicación con el público, sino que es el atributo formal del derecho" (2010, p. 215).

Ahora bien, sin perder de vista que todavía estamos en el comentario a la cuarta tesis de Kant, es importante señalar lo escrito por Teresa Santiago, ya que aclara que no hay ambiguiedad o contradicción en la obra de Kant respecto a su concepción del conflicto (o la guerra). Si bien Kant puede ser considerado uno de los filósofos que más han merecido el calificativo de pacifista, ello no significa que haya sido un autor timorato; él consideraba el conflicto como un factor necesario para el desarrollo moral y político, no solo de un Estado en específico, sino de la humanidad en general; desarrollo que implica, creo, una conquista paulatina de una paz perpetua:

Pero quizás una manera más adecuada de interpretar a Kant tiene que partir de que estamos frente a un pensador complejo, convencido de que la guerra cumple un propósito en la historia, esto es, que valiéndose del carácter egoísta y contradictorio de la naturaleza humana le obliga a enfrentarse porque sólo a través del conflicto y la guerra puede domeñar su naturaleza y aventurarse en la tarea de construir las instituciones políticas y jurídicas que perfeccionen a la especie (Santiago, 2004, p. 13).

El comentario de Teresa Santiago nos ayudará a conectar otra vez con las tesis de Kant sobre la historia universal, dado que en la quinta tesis el ilustrado de Könisberg señala que los humanos, confrontados entre sípor un impulso natural, se verán en la necesidad de conformar una sociedad civil con instituciones que salvaguarden el derecho de todos. La tesis la pone Kant en los siguientes términos: "El mayor problema de la especie humana, a cuya solución la naturaleza la apremia, es la instauración de una sociedad civil que administre el derecho general" (Kant, 1999, p. 80). La sociedad civil, como la llama Kant, es la instancia, y en esto no difiere de Thomas Hobbes y John Locke, donde se establece un derecho o marco jurídico que obliga y protege a todos, y que surge de una situación donde persiste una lucha de todos contra todos por imponer sus intereses egoístas. Con la instauración de la sociedad civil, postula Kant, se estarían estableciendo una serie de leyes que impedirían la imposición de unos intereses particulares sobre el interés de los demás; 
que impedirían que la libertad de cada sujeto entorpezca la libertad de los otros, y que, a la vez, favorecerían el desarrollo moral de todos los integrantes de la sociedad civil. El mismo Kant vuelve a utilizar la metáfora delárbol, parecida a la ya citada de sus escritos de pedagogía, solo que ahora lo hace para señalar las ventajas de la sociedad civil y los límites que debe poner a la libertad individual en su estado salvaje, en aras del bien común:

Sólo en un coto tal, como la asociación civil, obran las mismas propensiones el mejor resultado: como árboles en un bosque, donde uno trata de quitar al otro aire y sol, forzándose mutuamente a buscar por encima de ellos, hasta alzarse hermosos y erguidos; mientras que aquéllos que brotan en libertad y separados unos de otros, con sus ramas a placer, crecen raquíticos, corvos y torcidos. Toda cultura y arte que al hombre adornan, el más hermoso orden social, son frutos de la insociabilidad, que así misma se fuerza a disciplinarse y desarrollar por completo de este modo, mediante un arte esforzado, la semilla de la naturaleza (Kant, 1999).

Pero el proyecto ilustrado de Kant no solo apunta al progreso moral de un conjunto social determinado que es capaz de darse, mediante los conflictos debidamente canalizados, una serie de leyes para la convivencia pacífica. Dentro de su proyecto incluye el progreso y la paz a nivel mundial, que también tendrán que pasar por el conflicto antes de encontrar aquel conjunto de leyes que regule las relaciones entre todos los pueblos ${ }^{8}$. Si del conflicto deben surgir las leyes que regulen los conflictos de intereses existentes entre los individuos que viven en una comunidad, con mucha más razón el conflicto entre los diferentes Estados es el mal necesario para la creación de un marco legal o Constitución que ponga remedio a su antagonismo y salvaguarde sus intereses y su seguridad: "La Naturaleza ha usado también la incompatibilidad de los hombres, incluso de las grandes sociedades y cuerpos del Estado de tales criaturas, como un medio para encontrar, en su inevitable antagonismo, un estado de tranquilidad y seguridad" (Kant, 1999, pp. 82-83).

8 Kant, en "Para la paz perpetua", hace la siguiente comparación entre el plano de los individuos de una nación y el plano de los Estados de todo el orbe: "Los pueblos, en cuanto Estados, pueden considerarse como individuos que, en su estado de naturaleza (es decir, independientes de leyes externas), se perjudican por su coexistencia, y cada uno, en aras de su seguridad, puede y debe exigir del otro que entre con él en una constitución, semejante a la civil, en que se puedan garantizar a cada uno su derecho" (Kant, 1999, p. 319). 
Estamos ya en los principios séptimo y octavo de Kant sobre la historia universal. El séptimo lo enuncia así: "El problema de la instauración de una constitución civil perfecta depende del problema de una relación exterior legal entre los Estados, y no se puede resolver sin este último" (Kant, 1999, p. 82). Y el octavo principio, de esta otra forma: "Se puede considerar la historia de la especie humana en grande como ejecución de un plan escondido de la naturaleza para llegar al estado de una constitución perfecta del Estado en el interior y, respecto a este fin, también en el exterior, como única situación en que la naturaleza puede desarrollar por completo sus planes respecto a la humanidad (Kant, 1999, p. 86).

En general, estas dos tesis de Kant nos sugieren que los conflictos son un mal doloroso, pero necesario; sin ellos sería imposible un marco jurídico que funcionaría como caldo de cultivo para el desarrollo moral de la humanidad. Sin conflicto no habría una legislación que medie o regule las relaciones de todos los Estados del planeta, es decir, una especie de constitución mundial donde se indique cómo deben darse las relaciones entre los distintos pueblos para impedir que se destruyan unos a otros; o para evitar que los pueblos más pequeños vivan siempre con el temor de ser atacados por los más poderosos. Creo que, para Kant, esta legislación mundial es conveniente, por supuesto, para los Estados pacíficos o no tan poderosos, pero también para los de mayor poderío, y no solo porque con el marco legal en cuestión se lograría un mejor progreso moral de la humanidad, sino también porque permitiría que la guerra vaya desapareciendo poco a poco del planeta hasta alcanzar una paz perpetua y cosmopolita:

La misma guerra se convertirá paulatinamente en una empresa, no sólo artificial y de muy inseguro resultado para ambos lados, que habrá de pensarse detenidamente, sobre todo por las consecuencias que el Estado percibe en una siempre creciente carga de deuda [...] cuya cancelación es imprevisible, además de por la influencia que cada conmoción delEstado, por su industria tan concatenada, tiene en nuestra parte del mundo sobre los demás Estados, tan notoria, que éstos, amenazados por su propio peligro, se ofrecen, aunque sin respecto legal, a ejercer de árbitros, preparándose así, si bien de lejos, para un gran cuerpo de Estado futuro, de que el mundo anterior no ha dado ejemplo alguno. Aunque este cuerpo de Estado exista aún como un tosco esbozo, ya comienza a suscitarse, en cierto modo, un sentimiento en todos sus miembros, a los que interesa la conservación del conjunto; y esto proporciona la esperanza de que, por fin, después de muchas revoluciones 
de transformación, la naturaleza, respecto a su propósito supremo, una situación general cosmopolita como seno en que se desarrollarán todas las disposiciones originarias de la especie humana, llegarán algún día a darse (Kant, 1999, pp. 88-89).

Solo falta mencionar, ya para terminar, que el tipo de constitución a la que se refiere Kant es de corte republicano; pero esto quizás no quede tan claro en el escrito donde da sus nueve tesis sobre la filosofía universal, sino en el Conflicto de las facultades, donde explícitamente dirá que la Constitución que asegurará una relación pacífica entre naciones (incluso entre los individuos de una comunidad) no deberá ser diferente a la republicana:

En esta causa moral confluyen dos cosas: el derecho a que un pueblo no haya de verse obstaculizado por poder alguno para darse una constitución civil tal como le parezca bien a él mismo; en segundo lugar, la meta (que al mismo tiempo es un deber) de que aquella constitución de un pueblo sólo sea jurídica y moralmente buena en sí, cuando su naturaleza sea de tal índole que pueda evitar con arreglo a principios la guerra ofensiva, constitución que no puede ser sino la constitución republicana, cuando menos conforme a la idea de ésta, bajo la condición de poner trabas a la guerra (fuente de todos los males y de la depravación de las costumbres) y se asegure asíal género humano con toda su fragilidad del progreso hacia lo mejor de un modo negativo, para que cuando menos no se vea perturbado en ese avance (Kant, 2003b, pp. 160-161).

En suma, espero haber dejado claro que para Kant es muy importante el progreso, en especial el que tiene que ver con el mejoramiento moral, político e intelectual de las sociedades; todo esto sin perder de vista dos cosas: una, que el progreso en estos ámbitos no está exento del conflicto, ya que sin este todo quedaría en un estado de estancamiento donde no se buscaría el mejoramiento o perfeccionamiento de lo dado, y dos, que tal progreso debe darse a nivel mundial, evitando la exclusión de cualquier individuo o Estado, para que realmente se esté hablando de un verdadero desarrollo hacia mejor, es decir, un progreso incluyente que camine en medio de un mundo regido por leyes justas y no por la ley del más fuerte; un progreso que no esté preñado por las calamidades de la guerra; un "progreso humano" que no sea la simple fachada donde se encubren los intereses particulares, la opresión o agresión de los débiles, la mentira y la moral utilitarista; un progreso que no implique el aplastamiento de toda libertad, dignidad o moral humana. 
Como pudimos ver, Kant fue muy optimista respecto al progreso y al futuro que le esperaba a la humanidad si lograba darse, mediante la lucha, aquellas condiciones jurídicas y morales que hicieran posible la convivencia pacífica y respetuosa entre individuos y naciones. En el momento histórico en el que el autor de la Metafísica de las costumbres escribió, nadie previó que existiría un siglo XX donde, tras la fachada del progreso y del humanismo, se cometieron un sinfín de calamidades ${ }^{9}$ que orillaron a muchos a abandonarse en los brazos del pesimismo. Sin embargo, es innegable que fue también en el siglo de las dos grandes guerras cuando fue quedando más de manifiesto el poder emancipador de las luchas o conflictos sociales, ya que estos han dejado como saldo tanto la creación de instituciones que, al menos formalmente, salvaguardan los derechos humanos y la paz mundial, como la ampliación y el reconocimiento de derechos que antes no existían y eran inimaginables (derechos de género, de preferencias sexuales, de minorías étnicas o raciales, de los animales, etc.). Si dichos derechos e instituciones pueden parecerle a alguien insuficientes, esto no refuta a Kant: siempre tendremos el recurso de la lucha para conquistar el mundo que queremos.

9 El ejemplo emblemático de la denuncia de las calamidades del progreso es Walter Benjamin. Quién no ha leído y se ha quedado perturbado con su novena tesis sobre el concepto de la historia, donde interpreta la obra Angelus Novus, de Paul Klee: Se ve en él un ángel, al parecer, en el momento de alejarse de algo sobre lo cual clava la mirada. Tiene los ojos desencajados, la boca abierta y las alas tendidas. El ángel de la historia debe de tener ese aspecto. Su cara está vuelta hacia el pasado. En lo que para nosotros aparece como una cadena de acontecimientos, él ve una catástrofe única, que acumula sin cesar ruina sobre ruina y se las arroja a sus pies. El ángel quisiera detenerse, despertar a los muertos y recomponer lo despedazado. Pero una tormenta desciende del Paraíso y se arremolina en sus alas y es tan fuerte que el ángel no puede plegarlas. Esta tempestad lo arrastra irresistiblemente hacia el futuro, al cual vuelve las espaldas, mientras el cúmulo de ruinas sube ante él hacia el cielo. Tal tempestad es lo que llamamos progreso (Benjamin, 2007, pp. 69-70). 


\section{REFERENCIAS}

Arendt, H. (2003). Conferencias sobre la filosofía política de Kant. Barcelona, España: Paidós.

Benjamin, W. (2007). Conceptos de filosofía de la historia. Buenos Aires, Argentina: Terramar.

Granja Castro, D.M. (2010). Lecciones de Kant para hoy. Barcelona, España: Anthropos-UAM.

Granja Castro, D. M./Santiago Oropeza, T. (Coord.). (2011). Moral y Derecho. Doce ensayos filosóficos. Distrito Federal, México: Suprema Corte de Justicia de la Nación, UAM.

Hegel, G.W. F. (1984). Filosofía Real. México D.F.: F.C.E.

Hegel, G.W. F. (2006). El sistema de la eticidad. Buenos Aires, Argentina: Quadrata.

Höffe, O. (1986). Immanuel Kant. Barcelona, España: Herder.

Höffe, O. (2008). El proyecto político de la modernidad. Buenos Aires: FCEUAM.

Hobbes, T. (1992). Leviatán. Madrid, España: Alianza.

Honneth, A. (1997). La lucha por el reconocimiento: por una gramática moral de los conflictos sociales. Barcelona, España: Crítica.

Honneth, A. (2009). Crítica del agravio moral. México D.F.: F.C.E.-UAM.

Kant, I. (1985). Filosofía de la historia. México D.F.: F.C.E.

Kant, I. (1999). En defensa de la ilustración. Barcelona, España: Alba.

Kant, I. (2003a). Pedagogía. Madrid, España: Akal.

Kant, I. (2003b). El conflicto de las facultades. Madrid, España: Alianza.

Kant, I. (2007). Crítica del Juicio. Madrid, España: Tecnos.

Kant, I. (2009). Crítica de la razón pura. México D.F.: FCE-UAM-UNAM. 
Losurdo, D. (2013). La lucha de clases. Una historia política y filosófica. Barcelona, España: El Viejo Topo.

Marx, K./Engels, F. (1998). Manifiesto comunista. Barcelona, España: Crítica.

Santiago, T. (2004). Función y crítica de la guerra en la filosofía de I. Kant. Barcelona, España: Anthropos-UAM.

Taylor, C. (2003). El multiculturalismo y "la política del reconocimiento". México D.F.: F.C.E. 